\title{
Uma análise da inserção da sustentabilidade nos sistemas de crenças e de limites em empreendimentos hoteleiros em Bonito (MS)
}

\section{An analysis of the insertion of sustainability in in belief systems and boundaries of the hotel enterprises in Bonito (MS, Brazil)}

\author{
Rachel Matos Rocha, Milton Augusto Pasquotto Mariani, \\ Dyego de Oliveira Arruda, Luiz Miguel Renda dos Santos
}

RESUMO: A partir da atual necessidade de as organizações adotarem práticas sustentáveis como estratégias de vantagem competitiva, o objetivo deste estudo foi analisar como as práticas sustentáveis dos empreendimentos hoteleiros do município de Bonito/MS estão inseridas nos seus sistemas de crenças e de limites. A epistemologia desta pesquisa é construtivista, com abordagem qualitativa, pela relação de parceria entre sujeito e objeto a ser pesquisado, por meio da observação empírica. Utilizou-se os seguintes instrumentos de coleta de dados: a) documentos e b) entrevistas semiestruturadas. O principal instrumento de coleta de dados utilizado nesta pesquisa foram as entrevistas semiestruturadas. Através das entrevistas foi possível perceber que os três hotéis possuem muitas práticas de conservação dos recursos naturais e responsabilidade social. Concluiu-se que embora seus sistemas de crenças e de limites estejam bem delimitados, muitas de suas práticas sustentáveis não são percebidas pelos gestores como artefatos destes mesmos sistemas.

PALAVRAS CHAVE: Sistema de Crenças; Sistema de Limites; Sustentabilidade Empresarial; Empreendimentos Hoteleiros; Bonito-MS.

\begin{abstract}
Based on the current need for organizations to adopt sustainable practices as strategies of competitive advantage, the aim of this study was to analyze how the sustainable practices of hotel enterprises in Bonito / MS are inserted in their belief and boundary systems. The epistemology of this research is constructivist, with qualitative approach, by the relationship of partnership between subject and object to be researched, through empirical observation. The following data collection instruments were used: a) documents and b) semi-structured interviews. The main data collection instrument used in this research was the semi-structured interviews. Through the interviews it was possible to realize that the three hotels have many practices of conservation of natural resources and social responsibility. It was concluded that although their belief and boundary systems are well defined, many of their sustainable practices are not perceived by managers as artifacts of these same systems.
\end{abstract}

KEYWORDS: System of Beliefs; Limit System; Corporate Sustainability; Hotel Developments; Bonito-MS. 


\section{Introdução}

O uso indiscriminado dos recursos naturais e seu consequente desequilíbrio ao meio ambiente, motivou autoridades de diversos países, entre eles, o Brasil, a pensar estratégias com o propósito de maior conscientização da população e embasamento legal em prol do meio ambiente. As iniciativas resultantes desses eventos encontram-se no relatório emitido pela comissão de Brundtland, por meio da Organização das Nações Unidas (ONU, 1991). Nesse documento, encontra-se o conceito mais aceito de Desenvolvimento Sustentável, que consiste na defesa do avanço econômico, sem, contudo, comprometer o meio ambiente, permitindo às gerações futuras satisfazerem, também, suas necessidades de consumo, mas com qualidade de vida.

Essa questão, no Brasil, foi debatida na conferência Rio-92, também importante (mundialmente), com objetivo de buscar um mundo sustentável. $O$ resultado foi o documento Agenda 21. Com estes movimentos em prol da defesa do meio ambiente, o comportamento do consumidor começou a mudar, e as empresas percebendo o perfil de um consumidor mais exigente, viram-se estimuladas a também mudar.

Nessa perspectiva, toda organização busca se manter ativa no mercado, assim, adota medidas estratégicas para manutenção da competitividade em seu ramo de atuação. Sabe-se que a competitividade é a capacidade da organização em atingir um desempenho superando seus concorrentes (DIEHL; SOUZA, 2008). As organizações que caminham em busca de uma mudança comportamental para um modelo sustentável alcançam vantagem competitiva sobre as que não adotam uma postura socioambiental responsável, conforme aponta Kinlaw (1997), quando afirma que a sobrevivência e posição competitiva das organizações serão determinadas pelas estratégias utilizadas com o objetivo de permanecerem viáveis, ao mesmo tempo em que operam minimizando os impactos ambientais.

Nesse sentido, Simons (1995) determinou quatro constructos-chave a serem considerados para que se obtenha uma implementação estratégica bem-sucedida: valores centrais, riscos a serem evitados, incertezas estratégicas e aspectos críticos de desempenho. Dessa forma, são utilizados para que seja possível a operacionalização destes constructos: sistemas de crenças, sistemas de limites, sistemas de controles diagnósticos e sistemas de controles interativos, que juntos formam as alavancas de controle definidas por Simons (1995).

Com base na preocupação relativa à mudança do comportamento humano para lidar com o progresso e a defesa do meio ambiente. Este trabalho aborda questões de sustentabilidade empresarial. Para isso, adota o modelo triple bottom line (TBL) que abrange as dimensões econômicas, ambientais e sociais de forma que elas interajam entre si mostrando preocupação com a prosperidade econômica, qualidade ambiental e justiça social (ELKINGTON, 1998). 
Desse modo é importante levar em consideração que o desgaste ambiental além de ser afetado pela comercialização de bens é atingido também por algumas organizações prestadoras de serviços, como, por exemplo, as organizações do setor turístico que em sua grande maioria utilizam-se dos recursos naturais (URT, 2017).

Levando em consideração o modelo de sistemas de alavancas de controle, a questão norteadora deste estudo é: de que forma a sustentabilidade empresarial dos empreendimentos hoteleiros de Bonito, MS está inserida nos seus sistemas de crenças e de limites?

Para responder essa pergunta, o objetivo geral deste estudo é analisar como as práticas sustentáveis dos empreendimentos hoteleiros do município de Bonito/MS estão inseridas nos seus sistemas de crenças e de limites. Os objetivos específicos são: (i) identificar as práticas sustentáveis; (ii) destacar quais são as missões e regras estratégicas utilizadas pelas empresas de hotelaria; e (iii) comparar as práticas sustentáveis com as missões e regras dos hotéis.

O Brasil é um país com riquezas naturais, possuindo uma extensa fauna e flora, estando, assim, em uma posição importante na dimensão ambiental. Esse é um fator que tem grande peso na escolha dos turistas. De acordo com o site do Ministério do Turismo em 2017, o Brasil passou de $51^{\circ}$ (em 2013) para $27^{\circ}$ lugar no ranking dos países mais procurados para turismo, ocupando o $1^{\circ}$ lugar na dimensão de recursos naturais.

O motivo gerador da escolha dos empreendimentos de hotelaria como objeto de análise empírica deste estudo, decorre do aumento na demanda turística do Brasil, visto que, quando se trata da escolha por conta dos recursos naturais, o Brasil ocupa o primeiro lugar. Por este trabalho estar focado no tripé da sustentabilidade, optou-se por pesquisar em uma cidade turística cujo seu maior atrativo turístico seja seus recursos naturais. A escolha da cidade de Bonito/MS, como recorte empírico desta pesquisa, vinculou-se ao fato de que, das 17 edições do prêmio O MELHOR DE VIAGEM E TURISMO, essa cidade foi eleita 15 vezes como o melhor destino de ecoturismo, conforme consta no site da prefeitura municipal de Bonito. Além disso, ela é conhecida como a capital brasileira do ecoturismo

Depois da contextualização, e da exposição dos objetivos geral e específicos, a seguir o escopo teórico contemplará os conceitos da sustentabilidade bem como os de turismo e hotelaria sustentável, contemplando o conceito e como funcionam as alavancas de controle. Em seguida os procedimentos metodológicos, as discussões de resultados, as considerações finais e por fim, as referências bibliográficas.

\section{Escopo teórico}

O termo desenvolvimento sustentável, surgiu, originalmente, a partir do relatório de Brundtland, a partir do momento em que houve a percepção de que os recursos naturais são, de fato, esgotáveis. Após este relatório, o conceito de desenvolvimento sustentável da ONU (1991), passou a ser o mais aceito e utilizado, mundialmente. Com isso, acadêmicos e consultores 
empresariais, com o objetivo de sensibilizar as empresas, sugeriram que este termo deveria ser incorporado à linguagem empresarial (CINTRA, 2011).

Outro evento, igualmente importante para atrair os olhares das pessoas para a questão da preservação da natureza, foi a Eco-92 que ocorreu no período de 3 a 14 de junho de 1992, na cidade do Rio de Janeiro. Como fruto desse encontro, surgiu a Agenda 21, que teve como objetivo central estabelecer um novo padrão sobre as formas de como atingir o desenvolvimento ambientalmente responsável. Suas ações são pensadas de forma global, mas permite que se adapte de acordo com as necessidades nacionais e locais (AMAZONAS, 2014). Ainda, o mesmo autor considera que este documento trouxe valiosas contribuições a respeito de como as organizações poderiam continuar lucrativas atuando de forma ambientalmente consciente e socialmente responsável.

A Agenda 21 também teve uma forte contribuição sobre as atividades de turismo, assim, em 1994, após uma reunião do Conselho da Terra com o Conselho Mundial da Indústria de Viagens e Turismo (WTTC) e a Organização Mundial de Turismo (OMT), foi lançada a "Agenda 21 para Indústria de Viagens e Turismo" (AMORIM; RAMOS, 2003, p. 4). Tendo em vista que os recursos naturais e culturais são elementos essenciais para 0 funcionamento da indústria do turismo, o desenvolvimento sustentável é definido, por este documento, como um elemento essencial do negócio do turismo e reconhecido que a longo prazo os preços serão controlados pelas práticas sustentáveis (DIAS, 2003).

O evento mais recente, em relação ao desenvolvimento sustentável, ocorreu em setembro de 2015, em Nova York, mais precisamente na sede das Nações Unidas. A partir desse encontro, de chefes de nações, elaborouse o documento Agenda 2030, que é composto pelo conjunto de 17 objetivos de desenvolvimento sustentável agregadas a 169 metas (BRASIL,2018). É possível perceber que, com o passar dos anos, foram amadurecendo os significados e as preocupações com o desenvolvimento sustentável, transformando o pensamento humano que antes era apenas com a preocupação ambiental e em termos de relações públicas, para a percepção de que para atingir o desenvolvimento sustentável mundial, é preciso que todas as instituições estejam engajadas nesse propósito, sejam elas organizações governamentais e não-governamentais, órgãos públicos e privados, etc.

Na leitura de Leal $(2009$, p.1) uma organização é sustentável quando ela é "economicamente próspera, socialmente justa e ambientalmente responsável". No âmbito deste trabalho, considera-se os termos sustentabilidade e desenvolvimento sustentável, como similares em sua concepção, em conformidade com o conceito da ONU (1991), na medida em que estão relacionados a políticas públicas, enquanto 0 termo sustentabilidade empresarial está para objetivos relacionados a ações impulsionadas pelo setor privado (ARAÚJO; MENDONÇA, 2009).

Com base no exposto até o presente momento, percebe-se que 0 desenvolvimento sustentável está ligado à perspectiva de um país que está 
em crescimento, se mantendo ao longo do tempo. Dessa forma, se supõem, portanto, que seu propósito está mais inclinado a ser usado em políticas públicas do que em iniciativas privadas. Nesse bojo, Araújo e Mendonça (2009, p. 35) defendem que a sustentabilidade empresarial é vista como "a capacidade de autosustentar-se, de automanter-se". Ainda, de acordo com os autores,

O objetivo de qualquer organização é obter o maior retorno possível sobre o capital investido, ou seja, gerar lucro e remunerar os seus acionistas. Para tanto, utiliza-se de ferramentas disponíveis para estar à frente dos concorrentes, obtendo maiores margens e fatias de mercado (ARAÚJO; MENDONÇA, 2009 p. 36).

Essas concepções representam ferramentas de vantagem competitiva que podem estar relacionadas às práticas de sustentabilidade ambiental e responsabilidade social.

O campo da hospedagem, neste trabalho, está voltado à hotelaria, e reconhece a dinâmica do turismo nessa interface. Um exemplo que pode ser considerado é o trabalho das agências de turismo que sempre alia o processo das viagens e passeios à hospedagem dos clientes. Meio de hospedagem na definição de Swarbrooke (2000) pode ser entendido como um empreendimento de natureza pública ou privada que fornece serviços de acomodação, em suas atividades.

Como afirma Donaire (2008), a partir do gerenciamento ambiental surgem alguns benefícios econômicos e estratégicos, como: a empresa se adequa melhor aos padrões ambientais; suas relações com órgãos governamentais e comunidades ambientais se tornam melhores; sua imagem institucional melhora; além de economizar a partir da redução das multas ou penalidades.

Outra estratégia para atrair uma clientela preocupada com responsabilidade socioambiental, é aderir à certificação ambiental que é definida por Black e Crabtree (2007, p.20) como um

procedimento voluntário que define, avalia, monitora e fornece garantia por escrito de que um sistema de negócios, produto, processo, serviço ou gerenciamento atende a um requisito específico. Um logotipo comercializável (às vezes chamado de rótulo ecológico) é dado àqueles que se conformam ou atendem aos critérios, com o padrão pelo menos satisfazendo, mas geralmente acima, quaisquer requisitos regulatórios.

O autor Geertz (2014, p. 87) argumenta que as certificações ambientais relacionadas à indústria do turismo e hotelaria possuem três objetivos: (i) promover a implementação voluntária das práticas sustentáveis 
entre os gestores dos empreendimentos de hospedagem; (ii) aumentar a lucratividade dos meios de hospedagem certificados; e (iii) fornecer, durante o processo de reserva, aos clientes em potencial, informações mais precisas sobre o seu desempenho ambiental.

No Brasil surgiu a primeira iniciativa de certificação em sustentabilidade no turismo, em 2002, com o Programa de Certificação do Turismo Sustentável (PCTS) criado pelo Governo Federal, através da Norma Nacional para Meios de Hospedagem - Requisitos para Sustentabilidade (NIH-54:2004) que entrou em vigor em 2004, sendo interrompida em 2007 por falta de recursos financeiros e pela complexidade de sua aplicação (OLIVEIRA; ROSSETO, 2014). Atualmente a certificação vigente é a NBR 15401:2006, regulamentada pela ABNT, essa norma é resultante do PCTS e tem como objetivo especificar

\begin{abstract}
os requisitos relativos à sustentabilidade de meios de hospedagem, estabelecendo critérios mínimos específicos de desempenho em relação à sustentabilidade e permitindo a um empreendimento formular uma política e objetivos que levem em conta os requisitos legais e as informações referentes aos impactos ambientais, socioculturais e econômicos significativos (ABNT, 2006, p. 1).
\end{abstract}

No âmbito deste trabalho, como instrumentos de análise, serão adotadas as práticas sustentáveis contempladas na norma ABNT NBR 15401:2006, por ser regulamentada pelo Governo Federal e ser uma norma vigente. Vale destacar que, para fins deste trabalho, não é necessário que os hotéis (a serem estudados) tenham o selo desta certificação, o seu objetivo neste trabalho será apenas para orientação das práticas sustentáveis que podem vir a ser utilizadas nos hotéis em estudo.

Assim como o turismo tem forte representatividade ao afetar o meio ambiente, também este pode afetar diretamente suas atividades, pois "as regiões onde mais existem riscos de tais mudanças (zonas costeiras, pequenas ilhas, terras baixas e áreas úmidas) compreendem as principais atrações turísticas ao redor do mundo", como aponta Pires (2010, p. 9).

Nessa linha de pensamento, Association Internationale dès Expertes Cientifiques em Tourisme estipulou quatro características que representam um turismo responsável: (i) respeitar o meio ambiente; (ii) distribuir de forma igualitária os benefícios econômicos com a comunidade e os empresários; (iii) harmonia com a cultura e os espaços sociais da comunidade receptora a fim de não agredi-la; e (iv) contribuir com a formação de um turista mais atencioso e responsável (MONFORTE, 2007). Vejamos a concepção de alguns autores sobre o turismo sustentável.

Para Novaes (2012, p. 51), o turismo sustentável é aquela atividade que "atende às necessidades das gerações de hoje e das regiões receptoras, ao mesmo tempo em que protege e amplia as oportunidades para o futuro". O mesmo autor acredita que para se obter uma atividade 
turística e hoteleira sustentável, se faz necessária a articulação da indústria, do governo e dos recursos naturais e socioculturais entre si.

$\mathrm{Na}$ visão de Cooper et. al. (2007), o turismo sustentável permite a satisfação das necessidades atuais dos turistas e das regiões receptoras, ao mesmo tempo que garante oportunidades para o futuro. Trata-se de uma forma coerente de gerenciar os recursos de modo a satisfazer as necessidades econômicas, sociais e estéticas, mantendo, simultaneamente, a integridade cultural, os processos ecológicos, a diversidade biológica e os sistemas de apoio a vida.

Apesar de haver três dos 17 ODS's, que trazem referência direta ao negócio de turismo, é possível que os empreendimentos de turismo adotem atitudes a fim de se adaptar a todos os dezessete objetivos, assim como fizeram os autores Urt, Arruda e Mariani (2017), disposto no Quadro 1:

Quadro 1: Estratégias a partir das quais o turismo pode impactar nos vários ODS's.

Table 1: Strategies from which tourism can impact on various SDGs.

\begin{tabular}{|c|c|}
\hline $\begin{array}{c}\text { Objetivos do } \\
\text { Desenvolvimento } \\
\text { Sustentável } \\
\text { (ODS's) }\end{array}$ & Como o turismo pode impactar os ODS's? \\
\hline $\begin{array}{c}\text { (1) Erradicação da } \\
\text { pobreza }\end{array}$ & - Fomentar a economia local dos destinos turísticos, gerando renda. \\
\hline $\begin{array}{l}\text { (5) Igualdade de } \\
\text { gênero }\end{array}$ & $\begin{array}{l}\text { - Estímulo à melhoria da qualidade do emprego das mulheres - que } \\
\text { perfazem o maior contingente de pessoas empregadas no setor de } \\
\text { turismo, porém, em funções que exigem baixa qualificação e com } \\
\text { baixa remuneração; } \\
\text { - Implementação de programas de formação profissional e integração } \\
\text { de mulheres das comunidades locais. }\end{array}$ \\
\hline $\begin{array}{l}\text { (6) Água potável e } \\
\text { saneamento }\end{array}$ & $\begin{array}{l}\text { - Estímulo à programas de controle de poluentes; além de programas } \\
\text { de eficiência e economia de recursos hídricos; } \\
\text { - Criação de mecanismos de captação de água da chuva, além de } \\
\text { estratégias de reuso da água; } \\
\text { - Fomento à programas de gestão sustentável de recursos hídricos e } \\
\text { saneamento. }\end{array}$ \\
\hline $\begin{array}{c}\text { (7) Energia limpa e } \\
\text { acessível }\end{array}$ & $\begin{array}{l}\text { - Criação de programas de economia de energia, com a consequente } \\
\text { elaboração de métricas para o controle do uso de energia; } \\
\text { - Estímulo ao uso de energias provenientes de fontes renováveis; }\end{array}$ \\
\hline \multirow{2}{*}{$\begin{array}{l}\text { (8) Trabalho } \\
\text { decente e } \\
\text { crescimento } \\
\text { econômico }\end{array}$} & $\begin{array}{l}\text { - Encorajar a contratação de pessoas provenientes da comunidade } \\
\text { local, especialmente entre grupos vulneráveis; } \\
\text { - Fomento à ação empreendedora por parte das populações locais. }\end{array}$ \\
\hline & $\begin{array}{l}\text { - Melhorar a capacidade tecnológica dos destinos turísticos, em } \\
\text { especial das comunidades rurais, em termos de acesso às tecnologias } \\
\text { da informação e comunicação. }\end{array}$ \\
\hline $\begin{array}{l}\text { (10) Redução das } \\
\text { desigualdades }\end{array}$ & $\begin{array}{l}\text { - Contribuir para a renovação da infraestrutura urbana e o } \\
\text { desenvolvimento rural, reduzindo os desequilíbrios regionais e dando } \\
\text { às comunidades locais a oportunidade de prosperarem em seus locais } \\
\text { de origem. }\end{array}$ \\
\hline
\end{tabular}

Continua... 


\begin{tabular}{|c|c|}
\hline $\begin{array}{l}\text { Objetivos do } \\
\text { Desenvolvimento } \\
\text { Sustentável } \\
\text { (ODS's) }\end{array}$ & Como o turismo pode impactar os ODS's? \\
\hline \multirow[b]{3}{*}{$\begin{array}{l}\text { (11) Cidades e } \\
\text { comunidades } \\
\text { sustentáveis }\end{array}$} & $\begin{array}{l}\text { - Catalisar a transformação da paisagem urbana através da renovação } \\
\text { de espaços públicos, infraestruturas públicas, conectividade, além do } \\
\text { desenvolvimento de serviços locais e instalações recreativas } \\
\text { sustentáveis; }\end{array}$ \\
\hline & $\begin{array}{l}\text { - Estímulo à inovação e uso de tecnologias com vistas ao avanço rumo } \\
\text { à ideia de "cidades inteligentes", o que pode criar uma experiência } \\
\text { singular aos visitantes, além de melhorar a qualidade de vida da } \\
\text { população local. }\end{array}$ \\
\hline & $\begin{array}{l}\text { - Adotar práticas sustentáveis em relação à sua cadeia de } \\
\text { suprimentos; } \\
\text { - Incorporar informações relacionadas à sustentabilidade em seus } \\
\text { relatórios corporativos; } \\
\text { - Promover a cultura e os produtos locais, estimulando as práticas de } \\
\text { consumo sustentável entre turistas, empregados e comunidade local; } \\
\text { - Criar e difundir programas de gestão das perdas, com o consequente } \\
\text { reuso desses produtos - tais como o reuso de lixo orgânico em } \\
\text { sistemas de compostagem, para que se obtenham adubos naturais, } \\
\text { por exemplo. }\end{array}$ \\
\hline $\begin{array}{c}\text { (13) Ação contra a } \\
\text { mudança global do } \\
\text { clima }\end{array}$ & $\begin{array}{l}\text { - Criação e participação em alianças que objetivem combater a } \\
\text { mudança do clima; } \\
\text { - Implementação de programas que objetivem reduzir a emissão de } \\
\text { poluentes no clima, mitigando a "pegada ecológica" do } \\
\text { empreendimento. }\end{array}$ \\
\hline (14) Vida na água & $\begin{array}{l}\text { - Os empreendimentos em áreas costeiras; ou próximos a rios e lagos } \\
\text { devem implementar programas de conservação dos biomas aquáticos, } \\
\text { evitando a emissão de poluentes e estimulando turistas, empregados } \\
\text { e a comunidade local a adotarem práticas sustentáveis para com os } \\
\text { mares, rios e lagos. }\end{array}$ \\
\hline \multirow{2}{*}{ (15) Vida terrestre } & $\begin{array}{l}\text { - Proteger, restaurar e promover a utilização sustentável dos } \\
\text { ecossistemas terrestres; } \\
\text { - Gerir de forma sustentável as florestas; } \\
\text { - Combater a desertificação; } \\
\text { - Coibir a perda da diversidade biológica dos destinos turísticos. }\end{array}$ \\
\hline & $\begin{array}{l}\text { - Prevenção da violência e estímulo à consolidação da paz em áreas } \\
\text { que recentemente passaram por conflitos; } \\
\text { - Estímulo ao empoderamento das comunidades locais, estimulando- } \\
\text { as a tomarem, conjuntamente, decisões acerca do uso dos recursos } \\
\text { locais. }\end{array}$ \\
\hline $\begin{array}{l}\text { (17) Parcerias e } \\
\text { meios de } \\
\text { implementação }\end{array}$ & $\begin{array}{l}\text { - Os empreendimentos do setor de turismo devem engajar-se em } \\
\text { parcerias locais, regionais, nacionais e globais, com o objetivo de se } \\
\text { garantir mais eficazmente os ODS's; } \\
\text { - São fundamentais as parcerias entre empresas privadas do setor de } \\
\text { turismo, sociedade civil, governos e instituições de ensino/pesquisa, } \\
\text { com vistas ao planejamento e implementação de ações sustentáveis } \\
\text { nos destinos turísticos. }\end{array}$ \\
\hline
\end{tabular}

Fonte: URT; ARRUDA; MARIANI (2017, p. 7-8) com base em UNWTO (2016) e em United Nations (2017).

Source: URT; ARRUDA; MARIANI (2017, p. 7-8) based in UNWTO (2016) and United Nations (2017). 
Em vista disso, para efeitos de análise dos dados coletados na fase empírica desta pesquisa, nas dimensões de sustentabilidade serão usadas como parâmetro de comparação e análise as estratégias relacionadas aos ODS's inclusas no Quadro 1.

Contabilidade Gerencial para Atkinson et. al. (2015, p. 2) "é o processo de fornecer a gerentes e funcionários de uma organização informações relevantes, financeiras ou não financeiras, para tomadas de decisões, alocações de recursos, monitoramento, avaliação e recompensa por desempenho". Já Controle Gerencial, de acordo com Johnson e Kaplan (1993, p. 145), é o "processo pelo qual os gerentes asseguram que os recursos são obtidos e usados efetiva e eficientemente, na consecução dos objetivos da organização". No entendimento de Flamholtz (1979, p. 52), Controle Gerencial é "o processo de influenciar o comportamento dos membros da organização aumentando a probabilidade das pessoas se comportarem de modo a alcançar os objetivos da organização".

Para que o Controle Gerencial possa exercer sua função dentro da organização se faz necessária a utilização dos Sistemas de Controle Gerencial que, para Simons (1995, p. 5), são "rotinas formais baseadas em informação e procedimentos que gerentes usam para manter ou alterar comportamentos nas atividades organizacionais".

Com sua hipótese apoiada nos estudos de Mintzberg (1979) sobre estratégia organizacional, mais os estudos de aprendizagem organizacional de Argyris (1977), além dos estudos sobre sistemas de informação gerencial (HARLEZ; RONGE; SARENS, 2010), Simons (1995) alega ter criado o modelo de alavancas de controle (MAC), a partir de uma teoria de controle abrangente, demonstrando a forma como os gestores controlam as variadas estratégias, por não ser mais suficiente apenas planejá-las, pois também são resultantes das operações organizacionais e, por isso mesmo, exigem mecanismos diferentes para obter controle efetivo.

No sistema de alavancas de controle, de acordo com a Figura 1, os sistemas têm caráter positivo e negativo e podem encorajar ou restringir as ações (dos gestores e empregados). Eles se mostram opostos, em suas estruturas, pois Simons (1995) acredita que os Controle Gerenciais devem trabalhar com contradições. Isso permite que o Sistema de Controle Gerencial se adeque às mudanças contingenciais e permitam a inovação. Considerando a necessidade de adotar práticas de sustentabilidade ambiental e social na intenção de vantagem competitiva no mercado em que atua (CORAL, 2002), um fator contingencial para a organização e a implementação destas práticas sustentáveis como impulsionadora da inovação tecnológica (DARNALL, 2009), a adoção do sistema de alavancas de controle se faz viável para análise dos resultados empíricos. 


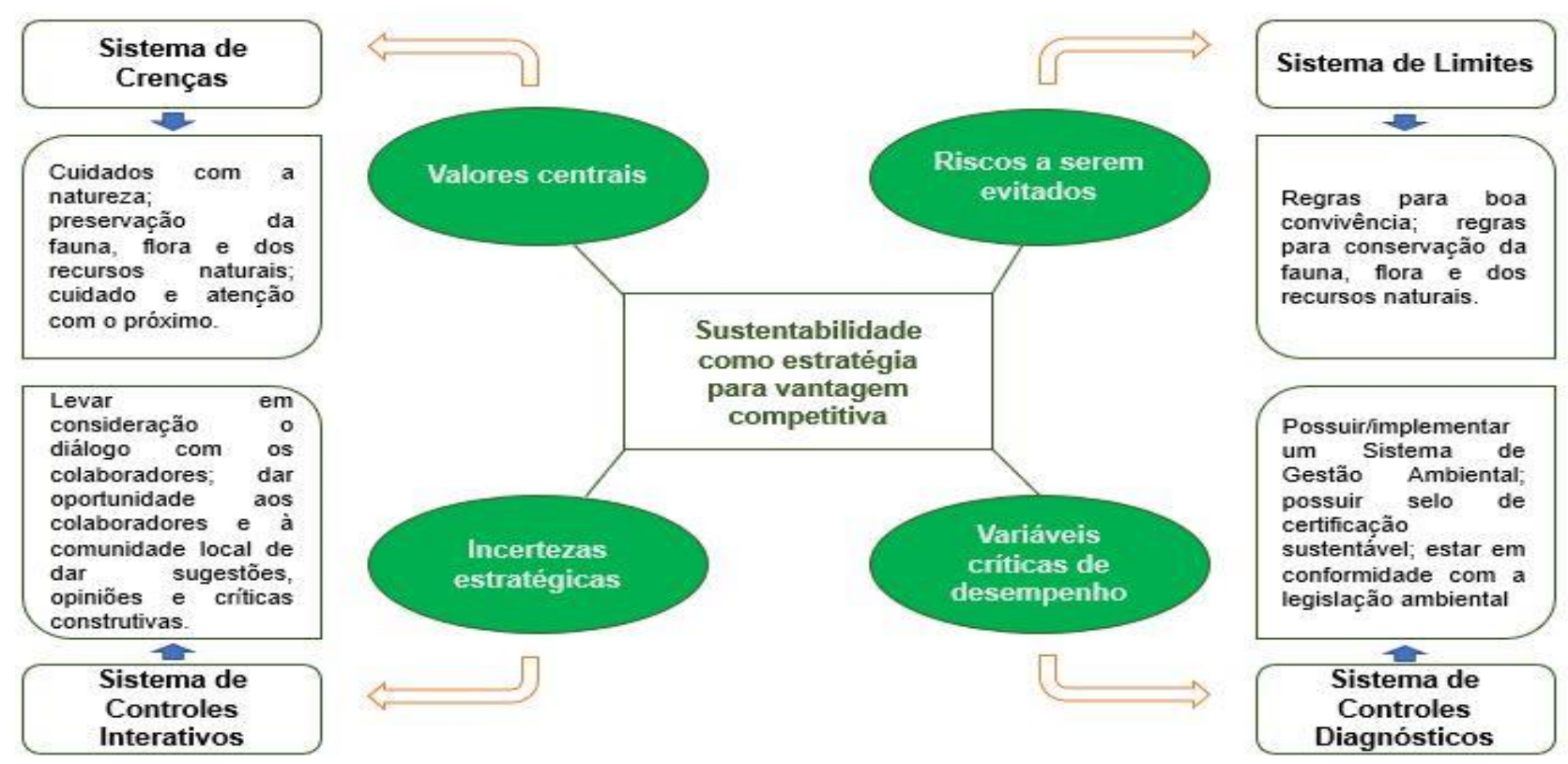

Figura 1: Práticas sustentáveis inseridas nas alavancas de controle.

Figure 1: Sustainable practices inserted in the control levers.

Fonte: Adaptado de Simons (1995).

Source: Adapted from Simons (1995).

No modelo original proposto por Simons (1995) das alavancas de controle, o elemento central deste modelo é a estratégia de negócios. Adaptando este modelo de forma a considerar as práticas de sustentabilidade como vantagem competitiva para a organização, a Figura 1 traz algumas atitudes que podem ser tomadas pelos gestores em relação a sustentabilidade social e ambiental, tendo em vista que o modelo original das alavancas comtempla satisfatoriamente a sustentabilidade econômica.

Para melhor entendimento do sistema proposto, faz-se necessário explicar o funcionamento e conceito de cada sistema. Para Simons (1995), os sistemas de crenças são as definições organizacionais utilizadas pela organização, com objetivo de comunicar de modo formal e enfatizar seus valores, propósitos e direção a fim de que estes sejam seguidos corretamente pelos seus subordinados. Esse sistema tem por fim inspirar os indivíduos para que os mesmos busquem, explorem, criem e engajem em ações apropriadas na organização. Esse sistema tem caráter positivo.

Já os sistemas de limites, na visão de Simons (1995), possui caráter negativo, de restrição, porém seu objetivo é o mesmo do sistema de crenças, que consiste em motivar os indivíduos a buscar oportunidades. Mas a forma de atingir seus objetivos é impondo limites, estabelecendo fronteiras aos funcionários para que eles não se engajam em comportamento de risco elevado. 


\section{Procedimentos metodológicos}

A epistemologia desta pesquisa é construtivista, com abordagem qualitativa, pelo fato da relação da parceria entre sujeito e objeto a ser pesquisado, por meio da observação empírica. No caso desta pesquisa, os hotéis pesquisados foram palco da observação direta, empírica, portanto. Trata-se, portanto, de uma pesquisa exploratória, pois investigou a possível inserção das práticas sustentáveis ao sistema de controle gerencial nos empreendimentos hoteleiros, uma "área onde há pouco conhecimento sistematizado" (VERGARA, 1990, p.4).

\section{Instrumentos de coleta de dados}

A fim de alcançar a profundidade dos dados, utilizou-se os seguintes instrumentos de coleta de dados: a) documentos e b) entrevistas semiestruturadas. O principal instrumento de coleta de dados utilizado nesta pesquisa foram as entrevistas semiestruturadas, que, juntamente com a análise dos sites e perfis em redes sociais, dos hotéis, além da observação direta, ajudaram a gerar os dados. A estrutura do protocolo da pesquisa utilizou quatro dimensões, como Malta (2012, p. 56) apresenta: (i) dimensão; (ii) indicadores de análise; (iii) questões do protocolo; e (iv) como as questões foram respondidas.

Desse modo, as entrevistas foram direcionadas apenas aos gerentes dos empreendimentos hoteleiro, que, pela responsabilidade da função que exercem, dominam com segurança as principais informações dos hotéis sob sua gestão.

\section{Caracterização dos pesquisados}

A escolha dos hotéis foi feita a partir de consulta ao site http://www.abih-ms.com.br/Hoteis.php?hoteis=bonito. Identificou-se que, em Bonito/MS, apenas cinco hotéis são associados à Associação Brasileira da Indústria de Hotéis $(\mathrm{ABIH})$. Esse critério de escolha decorreu do fato de esses hotéis estarem ligados à principal associação do ramo hoteleiro do Brasil, trazendo a oportunidade de verificar, por meio da pesquisa, se o aspecto de ser associado à $\mathrm{ABIH}$, reverte em termos de vantagem competitiva, ou não. Dos cinco, três, aceitaram participar da pesquisa, por meio da entrevista, um se recusou responder às perguntas e o último, das três vezes que a pesquisadora visitou, em nenhuma delas a gerente se encontrava no hotel. Vale ressaltar que dos cinco hotéis da lista, todos os gerentes são mulheres.

A realização das entrevistas e das observações diretas, deu-se no período do mês de junho/2018 e a análise do conteúdo dos websites foi realiza em outubro/2018. As entrevistas semiestruturadas aconteceram in $10 c 0$, nos respectivos hotéis. Foram gravadas, e, posteriormente, transcritas, com autorização das entrevistadas, a partir das suas assinaturas ao Termo de Consentimento Livre e Esclarecido. Os nomes dos hotéis são mantidos 
em sigilo, sendo nomeados, para fins de identificação nesta pesquisa, de Hotel A - H(A), Hotel B - $H(B)$ e Hotel C - H(C). Segue a caracterização:

$\mathbf{H}(\mathbf{A})$ - De gestão familiar, concebido a partir do desejo dos proprietários em adquirir um hotel, a ideia inicial era de o hotel ser no litoral, porém por serem e possuírem residência no Mato Grosso do Sul, os proprietários desistiram dessa ideia devido a dificuldade de locomoção.

H(B) - É um hotel de gestão familiar. Família vinda do Paraná, pai, mãe e dois filhos. O desejo inicial do pai era de possuir um pesqueiro no Pantanal, por questões pessoais não foi possível montar este negócio, durante a viagem, passaram por Bonito, e decidiram que seria onde iriam se instalar.

H(C) - A gestão deste hotel é de rede, apesar de os donos dessa rede serem irmãos. A respeito da formação da rede, se deu a partir de dois irmãos argentinos que estudavam fora e moravam em uma casa grande, e começaram a alugar os quartos desocupados, ao verem que estava dando certo, o negócio começou a ampliar para outras cidades.

Quadro 2: Detalhes gerais das respondentes.

Table 2: General Details of Respondents.

\begin{tabular}{|c|c|c|c|c|}
\hline Hotel & Cargo & $\begin{array}{c}\text { Tempo de } \\
\text { empresa }\end{array}$ & $\begin{array}{c}\text { Tempo de } \\
\text { gerência }\end{array}$ & Formação \\
\hline $\mathrm{H}(\mathrm{A})$ & Gerência & 14 anos & 7 anos & $\begin{array}{c}\text { Administração, possui } \\
\text { especialização }\end{array}$ \\
\hline $\mathrm{H}(\mathrm{B})$ & Gerência & 11 anos & 9 anos & Turismo \\
\hline $\mathrm{H}(\mathrm{C})$ & Gerência & 4 anos & 4 anos & Não informado \\
\hline
\end{tabular}

Fonte: Dados da pesquisa de campo.

Source: Field Survey Data

Considerou-se importante trazer esses detalhes gerais a respeito das respondentes com o intuito de, se necessário, servir como elementos de análise ao fazer inferência de alguma categorização.

\section{Técnica de análise de dados}

A técnica escolhida para análise dos dados foi a análise de conteúdo (BARDIN, 2009). A escolha pela técnica de análise de dados foi motivada pelo fato de o objetivo geral deste trabalho necessitar de uma análise mais aprofundada do conteúdo das mensagens, indo além de uma simples descrição dos dados encontrados, como aponta Moraes (1999). É possível, através dessa técnica, interpretar ao descrever o conteúdo dos dados obtidos, o que possibilita uma imersão nos resultados, através de uma estrutura de análise mais sistemática e objetiva. O processo de análise dos dados foi desenvolvido em 3 (três) etapas, como mostra a Figura 2. 
$1^{\text {a }}$ ETAPA - PRÉ-ANÁLISE

Leitura Flutuante - das respostas geradas pelas entrevistas e das possiveis informações referentes a açōes sustentáveis contidas nos websites dos hotéis que configuram nas atitudes sustentáveis.

$2^{a}$ ETAPA - EXPLORAÇÃO DO MATERIAL

Codificação - dos dados obtidos através das entrevistas e contidos nos websites dos hotéis, enumerando de acordo com o referencial teórico abordado no capítulo 2 .

\section{$3^{\text {a }}$ ETAPA - TRATAMENTO DOS RESULTADOS, INFERÊNCIA E INTERPRETAÇÃO}

Categorização - do material codificado, a fim de identificar como a sustentabilidade aparece nos discursos das entrevistadas e como a sustentabilidade está inserida na estrutura de alavancas de controle de Simons (1995)

Figura 2: Etapas da análise dos dados coletados.

Figure 2: Stages of analysis of the collected data. Fonte: Adaptado de Bardin (2009, p. 95). Source: Adapted from Bardin (2009, p. 95).

A análise dos resultados deu-se em 3 etapas, na primeira etapa foi feita uma leitura flutuante das entrevistas e, quando necessário, das informações contidas nos websites. Nesta etapa, a interpretação foi feita a partir dos blocos (3 dimensões da sustentabilidade e 2 alavancas de controle), para ficar claro se possuía as práticas, e de que forma essas práticas eram realizadas e também, quais artefatos de controle gerencial eram utilizados pelos hotéis, assim a etapa 1 da análise dos dados auxiliou para que os objetivos específicos (i) e (ii) fossem atingidos. A segunda etapa consistiu na exploração do material de análise, a fim de identificar quais práticas sustentáveis são utilizadas pelos hotéis e quais artefatos das alavancas de controle são utilizados pelos hotéis. Na terceira etapa, realizou-se a correlação entre as práticas sustentáveis e os artefatos dos sistemas de crenças e de limites.

\section{Resultados e discussões}

Através das entrevistas foi possível perceber que os três hotéis possuem muitas práticas de preservação das áreas naturais, fauna e flora, seja em atitudes, seja contribuindo em forma de apoio financeiro, contribuição com ONG's, projetos da comunidade local. Os três hotéis possuem formas de economizar energia, através do uso de lâmpadas mais econômicas, mantendo os frigobares dos apartamentos que não tivessem hóspedes desligados, através de sensores de calor. Porém o $H(A)$ possui um diferencial neste aspecto, através de placas de captação de energia solar para aquecer a piscina.

Em relação à economia de água, os três hotéis optaram por não trocar os enxovais dos apartamentos todos os dias, orientam que os hóspedes deixem as toalhas de banho no chão a fim de trocá-las. Um 
diferencial do $\mathrm{H}(\mathrm{A})$ é a captação da água da chuva para abastecer uma das piscinas, já o do $\mathrm{H}(\mathrm{B})$ é a utilização das águas que os ar condicionados soltam, para regar as plantas do estabelecimento do hotel. $\mathrm{OH}(\mathrm{B})$ possui uma pequena horta, seus frutos são utilizados para temperos das comidas feitas pelo restaurante, além de algumas fruteiras que suas frutas servem para compor o café da manhã para os hóspedes.

Os três hotéis são atuantes em ações a respeito da comunidade local. O quadro de pessoal de todos os hotéis é composto por mais de $90 \%$ de moradores locais. Também contribuem com patrocínios e apoio conforme podem. $\mathrm{O} H(\mathrm{~A})$ faz doações dos seus enxovais para um asilo e para um hospital da cidade onde se situa o hotel. $\mathrm{OH}(\mathrm{B})$ também doa enxovais para a população da comunidade local, além de sempre preferir comprar produtos de pequenos produtores e comerciantes da cidade em que atua.

A partir das práticas sugeridas no quadro 1 , anteriormente citado, elaborou-se 0 quadro 3 , incluindo as práticas dos hotéis pesquisados, de acordo com cada ODS, à medida em que fosse observado a prática destes objetivos.

Quadro 3: Práticas sustentáveis dos hotéis relacionadas aos 17 ODS`s. Table 3: Sustainable hotel practices related to 17 SDGs.

\begin{tabular}{|c|c|c|c|}
\hline $\begin{array}{c}\text { Objetivos do } \\
\text { Desenvolvimento } \\
\text { Sustentável } \\
\text { (ODS's) }\end{array}$ & H(A) & $\mathbf{H ( B )}$ & $\mathbf{H ( C )}$ \\
\hline $\begin{array}{c}\text { (1) Erradicação da } \\
\text { pobreza }\end{array}$ & $\begin{array}{c}\text { "100\% dos nossos } \\
\text { colaboradores são, } \\
\text { são locais, então a } \\
\text { gente tem, a nossa } \\
\text { contratação é 100\% } \\
\text { local" (entrevista) }\end{array}$ & $\begin{array}{c}\text { "95\%, é, da, dos } \\
\text { nossos empregados, } \\
\text { são da comunidade } \\
\text { local" (entrevista) }\end{array}$ & $\begin{array}{c}\text { "são todos locais, aqui } \\
\text { por ser, é meio difícil o } \\
\text { acesso a Bonito né, } \\
\text { então é tudo meio } \\
\text { longe, é tu, então são } \\
\text { poucos assim que são } \\
\text { de fora, então a maioria } \\
\text { é, é local mesmo." } \\
\text { (entrevista) }\end{array}$ \\
\hline (5) Igualdade de \\
gênero & $\begin{array}{c}\text { Possui mulheres em } \\
\text { cargos de gerência. } \\
\text { (observação direta) }\end{array}$ & $\begin{array}{c}\text { Possui mulheres em } \\
\text { cargos de gerência. } \\
\text { (observação direta) }\end{array}$ & $\begin{array}{c}\text { Possui mulheres em } \\
\text { cargos de gerência. } \\
\text { (observação direta) }\end{array}$ \\
\hline
\end{tabular}

Continua... 
...continuação.

\begin{tabular}{|c|c|c|c|}
\hline $\begin{array}{c}\text { Objetivos do } \\
\text { Desenvolvimento } \\
\text { Sustentável } \\
\text { (ODS's) }\end{array}$ & $H(A)$ & $H(B)$ & $\mathrm{H}(\mathrm{C})$ \\
\hline $\begin{array}{l}\text { (6) Água potável e } \\
\text { saneamento }\end{array}$ & $\begin{array}{l}\text { (i) "a gente também } \\
\text { colabora com, é, com } \\
\text { o IASB, que é o } \\
\text { Instituto das águas da } \\
\text { Serra da Bodoquena, } \\
\text { a gente faz a } \\
\text { compensação do } \\
\text { carbono né [...] a } \\
\text { nossa doação ela é } \\
\text { em dinheiro, mas } \\
\text { esse dinheiro é } \\
\text { revertido" (entrevista); } \\
\text { (ii) No caso da água, } \\
\text { a gente faz a } \\
\text { utilização da água da } \\
\text { chuva para uma das } \\
\text { piscinas, o restante } \\
\text { da água do } \\
\text { empreendimento a } \\
\text { gente tem um poço } \\
\text { artesiano, mas [...] a } \\
\text { gente tem um } \\
\text { documento que nos } \\
\text { permite utilizar essa } \\
\text { água por dez anos". } \\
\text { (entrevista) }\end{array}$ & $\begin{array}{l}\text { "a água do ar condicionado a } \\
\text { gente faz a captação pra } \\
\text { aguar as plantas, então essa } \\
\text { é uma coisa que a gente faz, } \\
\text { que mais, as toalhas, [...] a } \\
\text { gente, não, não troca as } \\
\text { toalhas nem a roupa de cama } \\
\text { todos os dias, as toalhas } \\
\text { somente quando os hóspedes } \\
\text { pedem, colocando elas na } \\
\text { pia, e a roupa de cama a } \\
\text { cada três dias, porque senão } \\
\text { vai muita água, muito } \\
\text { desperdício" (entrevista) }\end{array}$ & $\begin{array}{l}\text { "fazer trocas de toalhas } \\
\text { somente se, se houver, } \\
\text { se, se o hospede } \\
\text { solicitar, senão ela é } \\
\text { feita só depois de três } \\
\text { dias, então a gente não } \\
\text { troca, porque antes a } \\
\text { gente acabava trocando } \\
\text { as toalhas todos os } \\
\text { dias, né, ai a gente } \\
\text { optou por deixar uma } \\
\text { plaquinha nos } \\
\text { apartamentos e fazer a } \\
\text { troca só se houver } \\
\text { necessidade"(entrevista) }\end{array}$ \\
\hline $\begin{array}{c}\text { (7) Energia limpa } \\
\text { e acessível }\end{array}$ & $\begin{array}{c}\text { (i) "na parte de } \\
\text { energia, a gente tem } \\
\text { aí } 70 \% \text { das nossas } \\
\text { lâmpadas, são de } \\
\text { led,26510101+1 a } \\
\text { gente começou a } \\
\text { trocar o ano } \\
\text { passado," } \\
\text { (entrevista); (ii) } \\
\text { Energia solar para } \\
\text { aquecimento da água } \\
\text { de nossa piscina } \\
\text { aquecida. (website) }\end{array}$ & $\begin{array}{c}\text { "aqui são, são boas práticas, } \\
\text { por exemplo, pro hóspede } \\
\text { quando ele chega, a gente } \\
\text { pede, "ligou o ar } \\
\text { condicionado, janela fechada } \\
\text { e porta fechada" pra não } \\
\text { desperdiçar, a gente tem o, a, } \\
\text { aquela tomada que quando o } \\
\text { hóspede sai desliga toda a } \\
\text { energia do, do aparta, o } \\
\text { sensor, porque senão acaba } \\
\text { ficando luz, energia, quando } \\
\text { as camareiras fazem a } \\
\text { limpeza de apartamento, ar } \\
\text { condicionamento desligado, } \\
\text { TV desligada, é, o frigobar ele } \\
\text { é desligado, ele só é ligado } \\
\text { caso o hóspede compre } \\
\text { alguma coisa no frigobar da } \\
\text { recepção pra poder ligar, } \\
\text { então todos os frigobares são } \\
\text { desligados." (entrevista) }\end{array}$ & $\begin{array}{l}\text { "a gente também faz } \\
\text { aquilo que te falei do } \\
\text { frigobar, a gente } \\
\text { mantém ele desligado" } \\
\text { (entrevista) }\end{array}$ \\
\hline
\end{tabular}

Continua... 
...continuação.

\begin{tabular}{|c|c|c|c|}
\hline $\begin{array}{c}\text { Objetivos do } \\
\text { Desenvolvimento } \\
\text { Sustentável } \\
\text { (ODS's) }\end{array}$ & $H(A)$ & $H(B)$ & $\mathrm{H}(\mathrm{C})$ \\
\hline $\begin{array}{l}\text { (8) Trabalho } \\
\text { decente e } \\
\text { crescimento } \\
\text { econômico }\end{array}$ & $\begin{array}{l}\text { Políticas de valorização de } \\
\text { nossos colaboradores, } \\
\text { como: celebração anual da } \\
\text { empresa, ida à um passeio } \\
\text { de ecoturismo uma vez por } \\
\text { ano com os colegas de } \\
\text { trabalho, sorteio de vale } \\
\text { compras mensais, } \\
\text { celebração de aniversários } \\
\text { com bolo, apoio e incentivo } \\
\text { à capacitação profissional, } \\
\text { etc. (website) }\end{array}$ & $\begin{array}{l}\text { "o pintor que tá pintando, } \\
\text { ele é da comunidade, o, o } \\
\text { marceneiro que veio ele é } \\
\text { da comunidade" } \\
\text { (entrevista) }\end{array}$ & \\
\hline $\begin{array}{l}\text { (10) Redução das } \\
\text { desigualdades }\end{array}$ & $\begin{array}{l}\text { "a gente trabalha no } \\
\text { sentido de apoiar a } \\
\text { comunidade seja, ONGs } \\
\text { que fazem trabalhos com } \\
\text { crianças, seja a } \\
\text { comunidade do entorno } \\
\text { mesmo, né, a parte de...a } \\
\text { proprietária é madrinha da } \\
\text { creche que fica no bairro, a } \\
\text { gente participa das ações } \\
\text { que tem da comunidade". } \\
\text { (entrevista) }\end{array}$ & $\begin{array}{c}\text { "tudo que é garrafa, vai } \\
\text { pra casa do vidro, que é, } \\
\text { que é, que é aquele } \\
\text { pessoal que pega pra } \\
\text { poder revender" } \\
\text { (entrevista) }\end{array}$ & \\
\hline $\begin{array}{l}\text { (11) Cidades e } \\
\text { comunidades } \\
\text { sustentáveis }\end{array}$ & $\begin{array}{l}\text { Melhoria contínua da } \\
\text { eficácia do sistema de } \\
\text { gestão da sustentabilidade } \\
\text { suportada pela } \\
\text { racionalização do uso dos } \\
\text { recursos naturais. (website) }\end{array}$ & & \\
\hline $\begin{array}{c}\text { (13) Ação contra a } \\
\text { mudança global } \\
\text { do clima }\end{array}$ & $\begin{array}{c}\text { Realizamos o trabalho de } \\
\text { neutralização de carbono, } \\
\text { contribuindo com quantia } \\
\text { em dinheiro para a } \\
\text { organização IASB, que } \\
\text { desenvolve o projeto } \\
\text { Plante Bonito, em que a } \\
\text { quantia ofertada é } \\
\text { convertida em árvores. } \\
\text { (websites) }\end{array}$ & & \\
\hline
\end{tabular}

Continua... 
...continuação.

\begin{tabular}{|c|c|c|c|}
\hline $\begin{array}{c}\text { Objetivos do } \\
\text { Desenvolvimento } \\
\text { Sustentável } \\
\text { (ODS's) }\end{array}$ & $H(A)$ & $H(B)$ & $H(C)$ \\
\hline (14) Vida na água & & $\begin{array}{l}\text { "a gente faz a limpeza do rio, } \\
\text { [...] porque pode descer né, a, a } \\
\text { limpeza de rio, a nossa rede de } \\
\text { esgoto ela é } 100 \% \text { ligada na } \\
\text { [empresa de saneamento], não } \\
\text { tem nada que vai pro rio, [...] } \\
\text { nós temos ah, as lixeiras } \\
\text { adequadas, as lixeiras elas não } \\
\text { podem ficar próxima ao rio, } \\
\text { elas tem que ficar do outro } \\
\text { lado, que foi uma medida que a } \\
\text { gente tomou, pra não correr } \\
\text { chorume." (entrevista) }\end{array}$ & \\
\hline (15) Vida terrestre & $\begin{array}{l}\text { Produzimos todo } \\
\text { nosso adubo que é } \\
\text { suficiente para } \\
\text { manter nosso jardim } \\
\text { sempre verde e } \\
\text { florido.. (website) }\end{array}$ & $\begin{array}{l}\text { "aonde o hotel foi construído, } \\
\text { [...] era um brejo e era } \\
\text { completamente desmatado à } \\
\text { beira do rio, então, é, todas as } \\
\text { árvores foram plantadas pelos } \\
\text { proprietários, então assim, a } \\
\text { part, essa parte de } \\
\text { reflorestamento foi feita pelos } \\
\text { proprietários" (entrevista) }\end{array}$ & \\
\hline $\begin{array}{l}\text { (17) Parcerias e } \\
\text { meios de } \\
\text { implementação }\end{array}$ & $\begin{array}{l}\text { "das festas } \\
\text { populares que tem, } \\
\text { como são as } \\
\text { quermesses, né, do } \\
\text { padroeiro, a gente } \\
\text { participa, é, a parte } \\
\text { de ajuda mesmo } \\
\text { pras ONGs, né, aí a } \\
\text { gente tem "família } \\
\text { legal", "visão de } \\
\text { vida", "projeto mirim } \\
\text { ambiental", então } \\
\text { todas essas } \\
\text { organizações } \\
\text { precisando eles já } \\
\text { sabem aonde eles } \\
\text { podem procurar o } \\
\text { apoio, né, a ajuda, } \\
\text { então é nesse } \\
\text { sentido. "(entrevista) }\end{array}$ & $\begin{array}{l}\text { "nós ajudamos várias ONGs } \\
\text { locais, a gente faz doação a, } \\
\text { tanto de mensalidade, quanto } \\
\text { de algo aleatório que eles } \\
\text { pedem, enxoval que a gente } \\
\text { não utiliza mais, porque pro } \\
\text { hotel não fica bom, mas pra } \\
\text { gente usar em casa, eles são } \\
\text { doados também, ah, eu tenho } \\
\text { umas luminárias em frente a } \\
\text { cada apartamento, que é feito } \\
\text { por um senhor, meu vizinho, } \\
\text { que ele faz na mão mesmo, de } \\
\text { cipó de árvore, eu vendo pra } \\
\text { casa do vidro, e os meus copos } \\
\text { são todos recicláveis da casa } \\
\text { do vidro [...] nós fazemos parte } \\
\text { de todas as associações, tanto } \\
\text { de agência, quanto de hotel, } \\
\text { quanto do convention, quanto } \\
\text { da... hotelaria, agência, } \\
\text { convention," (entrevista) }\end{array}$ & \\
\hline
\end{tabular}

Fonte: a partir das entrevistas e websites adaptado de Urt, Arruda e Mariani (2017).

Source: from interviews and websites adapted from Urt, Arruda and Mariani (2017) 
Os objetivos 1, 5, 6 e 7 são observados nos três hotéis entrevistados. Desse modo, é possível perceber que todo ou quase todo o quadro de funcionários dos hotéis pesquisados é composto por moradores da comunidade local, atingindo o objetivo 1, por gerar renda à população local. Os três hotéis possuem mulheres em cargos de gerência, atingindo assim o ODS 5. Práticas de economia e consumo de água e energia, estão presentes nos três hotéis pesquisados.

Percebe-se que o $\mathrm{H}(\mathrm{A})$ atinge todos os objetivos do quadro 1 , o que demonstra o quanto este empreendimento hoteleiro está engajado nas suas práticas sustentáveis, ambiental e social. A partir desta constatação, concluise que o $\mathrm{H}(\mathrm{A})$ possuir tantas práticas sustentáveis, pode significar que estas estejam inseridas em seus sistemas de crenças, ainda que os gestores não tenham essa percepção.

Pode-se considerar que as práticas sustentáveis, social e ambiental, do $H(B)$ também façam parte de seus sistemas de crenças, ainda que em sua maioria não sejam percebidas pelos seus gestores como tal.

Quanto à identificação do sistema de crenças de cada empreendimento hoteleiro, para identificar os artefatos utilizados pelos hotéis, foi investigado qual a missão de cada hotel. Assim, no $H(A)$ sua missão está em tratar o cliente de forma que o mesmo se sinta em casa, na extensão de sua casa. No $\mathrm{H}(\mathrm{B})$, a missão está focada nos colaboradores do hotel, tratá-los como parte da família dos proprietários, já que o hotel é familiar, pois, conforme justifica a respondente, quando o colaborador sente seu local de trabalho como um lugar acolhedor, ele se sentirá realizado e feliz, e isso se refletirá no seu atendimento e acolhimento dos hóspedes. A missão do $H(C)$ está focada em atender e acolhe bem o hóspede, com simpatia.

Já o sistema de limites foi investigado a partir dos artefatos de regras, códigos de conduta, atenção às legislações. É possível perceber que o sistema de limites, é bem definido no $H(A)$, também é perceptível que a criação do regulamento interno se deu após algum possível inconveniente com os colaboradores, confirmando a proposta de Simons (1995) que traz a necessidade deste sistema a fim de estabelecer fronteiras aos funcionários para que estes não se engajem em comportamentos de risco elevado. $O$ $H(B)$ também tem sistema de limites bem definido através de regras gerais pré-estabelecidas a serem seguidas pelos funcionários, assim como regras específicas de acordo com cada departamento do hotel. $\mathrm{O}$ regulamento interno do $\mathrm{H}(\mathrm{C})$ está voltado ao bom atendimento ao cliente, esse é o direcionamento dados aos colaboradores.

A partir dessas análises individuais, foi feita uma correlação dos constructos de sustentabilidades e de sistema de crenças e sistema de limites, dispostos no quadro 3. 
Quadro 4: A sustentabilidade inserida nas alavancas de controle.

Table 4: The sustainability inserted in the control levers.

\begin{tabular}{|c|c|c|c|}
\hline & $H(A)$ & $H(B)$ & $H(C)$ \\
\hline $\begin{array}{c}\text { SISTEMA DE } \\
\text { CRENÇAS }\end{array}$ & $\begin{array}{c}\text { Esse sistema está bem } \\
\text { definido. Pontualmente, } \\
\text { a dimensão destacada } \\
\text { neste sistema é a } \\
\text { econômica, pois seu } \\
\text { foco está em atender } \\
\text { com excelência o } \\
\text { hóspede. Constata-se, } \\
\text { porém, a inserção } \\
\text { indireta das dimensões } \\
\text { social e ambiental nesta } \\
\text { alavanca, visto que } \\
\text { muitas das práticas } \\
\text { sustentáveis sociais e } \\
\text { ambientais do hotel são } \\
\text { voltadas para melhor } \\
\text { atender ao cliente. }\end{array}$ & $\begin{array}{l}\text { A priori, não se mostrou } \\
\text { bem definido, mas na fala } \\
\text { da respondente foi } \\
\text { possível perceber que o } \\
\text { foco está na gestão de } \\
\text { pessoas, ou seja, neste } \\
\text { empreendimento, } \\
\text { considera-se fundamental } \\
\text { tratar muito bem seus } \\
\text { funcionários, como se } \\
\text { fossem da família. As } \\
\text { dimensões inseridas } \\
\text { nesse sistema são as } \\
\text { sociais e econômicas. }\end{array}$ & $\begin{array}{c}\text { Não está bem } \\
\text { definida nem bem } \\
\text { divulgada. } \\
\text { Percebe-se que } \\
\text { não há divulgação } \\
\text { por parte da alta } \\
\text { direção para as } \\
\text { demais franquias. }\end{array}$ \\
\hline $\begin{array}{l}\text { SISTEMA DE } \\
\text { LIMITES }\end{array}$ & $\begin{array}{l}\text { Apesar de não possuir } \\
\text { um estatuto ou código } \\
\text { de ética próprios, esse } \\
\text { sistema está bem } \\
\text { definido. A dimensão } \\
\text { encontrada nesse } \\
\text { sistema é a social. }\end{array}$ & $\begin{array}{l}\text { Este sistema está bem } \\
\text { definido, e é direcionado } \\
\text { de acordo com o setor. A } \\
\text { sustentabilidade } \\
\text { contemplada neste } \\
\text { sistema é a social. }\end{array}$ & $\begin{array}{c}\text { Entende-se que } \\
\text { este sistema está } \\
\text { voltado ao bom } \\
\text { atendimento ao } \\
\text { hóspede. A } \\
\text { dimensões } \\
\text { inseridas neste } \\
\text { sistema são a } \\
\text { social e a } \\
\text { econômica. }\end{array}$ \\
\hline
\end{tabular}

Fonte: Autora a partir de entrevistas, análise dos websites e observação direta.

Source: Author from interviews, website analysis and direct observation.

Dessa forma, foi possível identificar que dentro dos sistemas de crenças e limites, havia a manifestação da dimensão social, ambiental e econômica. A dimensão social é percebida nesses sistemas a partir da valorização dos colaboradores por parte dos gestores, especialmente nos hotéis de gestão familiar, tanto no sentido de proporcionar um ambiente seguro de se trabalhar como no sentido de dar "voz" em algumas tomadas de decisões da organização.

\section{Considerações finais}

Ao final do trabalho, constata-se, que o objetivo geral, analisar como as práticas sustentáveis dos empreendimentos hoteleiros do município de Bonito/MS estão inseridas nos seus sistemas de crenças e de limites, foi alcançado pelo fato de que observou-se que o sistema de crenças está bem delimitado tanto no $H(A)$, como no $H(B)$. No $H(C)$, essa percepção não está clara, porém durante a fala da respondente foi possível identificar a delimitação desse sistema. No $H(A)$ há uma inserção direta da sustentabilidade econômica e indireta das sustentabilidades social e ambiental. No $H(B)$ as sustentabilidades manifestadas são a social e a econômica. No $\mathrm{H}(\mathrm{C})$, apenas a sustentabilidade econômica. 
Ao analisar o sistema de limites foi possível constatar que nos três hotéis estudados, esse sistema está bem delimitado, sendo que nos hotéis $H(A)$ e $H(B)$, manifesta-se apenas a sustentabilidade social, e no $H(C)$ manifesta-se as dimensões social e econômica. $O$ sistema de crenças e 0 sistema de limites se confundem no $\mathrm{H}(\mathrm{C})$.

Como sugestões na utilização de suas práticas sustentáveis como vantagem competitiva e auxílio em tomadas de decisões gerenciais, sugerese aos hotéis $H(A)$ e $H(B)$ que definam, formalizem e compartilhem, tanto com seus colaboradores como com seus clientes, suas crenças e missões, com isso será possível inserir de forma mais eficaz as práticas sustentáveis já utilizadas por ambos os hotéis em seus respectivos sistemas de controle gerencial. Quanto ao $\mathrm{H}(\mathrm{C})$, antes de tomar alguma atitude em relação aos seus sistemas de crenças e de limites, seria interessante fazer uma aproximação da casa franquiada com a casa sede, compartilhando com a primeira quais as crenças e missões da rede hoteleira, assim como suas regras e regulamentos, tal atitude pode ajudar a casa franquiada a ser mais eficiente e eficaz quanto ao planejamento e controle de suas decisões.

Sugere-se, tanto para o público acadêmico que tenham interesse nessa temática, como para os profissionais de controle gerencial e de gestão estratégica, a aplicação da análise feita no presente estudo em outras áreas de negócio, pois embora o objeto deste trabalho tenha se vinculado aos meios de hospedagem, é possível realizar essa mesma investigação da presença da sustentabilidade empresarial nos sistemas de controle gerencial, a partir da abordagem das alavancas de controle em outros setores de negócios, seja vinculado ao Turismo ou não. Conforme constatado no referencial teórico, essa abordagem de controle, por ter uma natureza flexível, atemporal e aplicável a artefatos financeiros e não financeiros, justifica a sugestão apresentada.

\section{Referências}

ABNT - Associação Brasileira de Normas Técnicas (2006) - NBR 15401: meios de hospedagem: sistema de gestão da sustentabilidade: requisitos. Rio de Janeiro. Disponível em <http://abnt.org.br/paginampe/biblioteca/files/upload/ anexos/pdf/7515428786c2ed12564fc0f36afbc2a5.pdf>. Acesso: 19 fev. 2018.

AMAZONAS, I. T. Gestão ambiental na hotelaria: tecnologias e práticas +sustentáveis aplicadas nos hotéis de João Pessoa-PB. $2014.124 p$. Dissertação (Mestrado em Meio Ambiente) - Programa de Pós-Graduação em Desenvolvimento e Meio Ambiente, UFPB, João Pessoa, PB.

AMORIM, C.G.; RAMOS, S.E.V.D.C. Programa Hóspede da Natureza: uma ferramenta para educação ambiental. In: SEMINÁRIO DE PESQUISA EM TURISMO DO MERCOSUL, 1., 2003 Caxias do Sul. Anais... Caxias do Sul: UCS, 2003. 1 CD ROM.

ARAÚJO, G.C. de; MENDONÇA, P.S.M. Análise do processo de implantação das normas de sustentabilidade empresarial: um estudo de caso em uma agroindústria frigorífica de bovinos. Revista de Administração Mackenzie (Mackenzie Management Review), São Paulo, v. 10, n. 2, p. 31-56, mar./abr., 2009. 
ARGYRIS, C. Organizational learning and management information systems. Accounting, Organizations and Society, Issue, v. 2, n. 2, p. 113123, 1977.

ASSOCIAÇÃO BRASILEIRA DA INDÚSTRIA DE HOTÉIS. A indústria do turismo no mundo e no Brasil. $A B I H$ Nacional. Disponível em: $<$ www.abih.com.br $>$. Acesso em 23/07/2017.

ATKINSON, A.A; KAPLAN, R.S.; MATSUMURA; YOUNG, S.M. Contabilidade gerencial: informação para tomada de decisão e execução da estratégia. 4. ed. São Paulo: Atlas, 2015.

BARDIN, L. Análise de conteúdo. Lisboa: Edições 70, 2009.

BRASIL. Agenda 2030. Transformando nosso mundo: Agenda 2030 para o desenvolvimento sustentável. Disponível em: <www.agenda2030.com.br $>$ Acesso em: 18 dez 2018.

CINTRA, Y.C. A integração da sustentabilidade às práticas de controle gerencial das empresas no Brasil. 2011. 198p. Tese (Doutorado em Controladoria e Contabilidade) - Faculdade de Economia, Administração e Contabilidade da Universidade de São Paulo, São Paulo - SP.

COOPER, C. et al. (Org.) Turismo, princípios e práticas. 3. ed. Porto Alegre: Brookman, 2007.

CORAL, E. Modelo de planejamento estratégico para a sustentabilidade empresarial. 2002. 282p. Tese (Doutorado em Engenharia de Produção) Universidade Federal de Santa Catarina, Florianópolis - SC.

DARNALL, N. Regulatory stringency, green production offsets, and organizations' financial performance. Public Administration Review, WileyBlackwell. v. 69, n. 3, p. 418-434, 2009.

HARLEZ, Y. RONGE, Y. and SARENS, G. (2010). The interactive use of management control systems: Review and discussion of empirical literature. In Annual congress of the European Accounting Association (Tampere, Finland), 2010.

DIAS, R. Turismo Sustentável e Meio Ambiente. São Paulo: Atlas, 2003.

DIAS, R. Gestão ambiental responsabilidade social e sustentabilidade. 2. ed. São Paulo: Atlas S.A., 2011.

DIEHL, C.A.; SOUZA, M.A. Alavancas de Controle: identificando o alinhamento estratégico. Revista del Instituto Internacional de Costos. Paraná, n.2, p.4166, enero/julio, 2008.

DONAIRE, D. Gestão ambiental na empresa. 2. ed. São Paulo: Atlas, 2008.

ELKINGTON, J. Cannibals with Forks: the Triple Bottom Line of $21^{\text {st }}$ Century Business. Gabriola Island, BC (CA), 1998.

GEERTS, Wouter. Environmental certification schemes: Hotel managers' views and perceptions. International Journal of Hospitality Management, v. 39, p. 87-96, 2014.

FLAMHOLTZ, E. Organizational control systems as a managerial tool. California management review, Berkeley, v. 22, n. 2, p. 50-59, dez.,1979.

GEERTS, Wouter. Environmental certification schemes: Hotel managers' views and perceptions. International Journal of Hospitality Management, v. 39, p. 87-96, 2014. 
JOHNSON, H.T. \& KAPLAN, R.S. Contabilidade gerencial: a restauração da relevância da contabilidade nas empresas. Rio de Janeiro: Campus, 1993.

KINLAW, D. C. Empresa competitiva e ecológica: desempenho sustentado na era ambiental. São Paulo: Makron Books, 1997.

LEAL, C.E. A era das organizações sustentáveis. Revista Eletrônica Novo Enfoque da Universidade Castelo Branco, Realengo, v. 8, n. 8, p. 1-12, 2009.

MALTA, M.C.M. A Sustentabilidade Aplicada na Gestão dos Empreendimentos Hoteleiros em Campo Grande, MS. 2012. 111p. Dissertação (Mestrado em Administração) - ESAN. Universidade Federal de Mato Grosso do Sul, Campo Grande - MS, 2012.

MINISTÉRIO DO TURISMO. Brasília, 2017. Disponível em: http://www.turismo.gov.br/ Acesso em: 16 jan. 2019.

MINTZBERG, $\mathrm{H}$. The structuring of organization: A synthesis of the research. United States: Prentice-Hall, 1979.

MORAES, R. Análise de conteúdo. Revista Educação. Porto Alegre, v. 22, n. 37, p. 7-32, 1999.

NOVAES, M.B.C. A discussão sobre sustentabilidade e o desenvolvimento de competências gerenciais nas organizações: investigando de forma cooperativa atores, estruturas, discursos e ações. 2012. 227p. Tese (Doutorado em Administração de Empresas) - FAU, Universidade Presbiteriana Mackenzie, São Paulo - SP, 2012.

OLIVEIRA, M. de A. S.; ROSSETTO, Adriana Marques. Modelo Integrado de Sustentabilidade e Competitividade em Meios de Hospedagem [MISCMH]. ROSA DOS VENTOS-Turismo e Hospitalidade, v. 6, n. 4, 2015.

ONU - Organização das Nações Unidas. Relatório da comissão mundial sobre meio ambiente e desenvolvimento. Nosso futuro comum. 2. ed. São Paulo: FGV, 1991.

PIRES, P. S. Turismo e Meio Ambiente: relação de interdependência. In: Arlindo Philippi Jr; Dóris Van de Meene Ruschmann. (Org.). Gestão Ambiental e Sustentabilidade no Turismo. 1ed.São Paulo: Manole, 2010, v. 01, p. 3-29.

PREFEITURA MUNICIPAL DE BONITO. Bonito, 2018. Disponível em: http://www.bonito.ms.gov.br/. Acesso em: 16 jan. 2019.

SIMONS, R. Levers of control: how managers use innovative control systems to drive strategic renewal. Boston: Harvard Business School, 1995.

SWARBROOKE, J. Turismo Sustentável: turismo cultural, ecoturismo e ética. Vol 5, São Paulo: Aleph, 2000.

URT, M.C.M. As Organizações e o Turismo sustentável: uma análise no contexto do Código de Ética e Conduta Ambiental da Associação Roteiros de Charme do Brasil. 2017. 127p. Dissertação (Mestrado em Administração) ESAN, Universidade Federal de Mato Grosso do Sul, Campo Grande, 2017.

URT, M.C.M.; ARRUDA, D.O.; MARIANI, M.A.P. Hotelaria de Charme e os Desafios da Agenda para o Desenvolvimento Sustentável no Turismo/Charm Hotels and the Challenges of Sustainable Development Agenda in Tourism. ROSA DOS VENTOS-Turismo e Hospitalidade, v. 10, n. 1, 2017.

VERGARA, S. C. Tipos de pesquisa em administração. São Paulo: Atlas, 1990. 


\section{Agradecimento}

À Coordenação de Aperfeiçoamento de Pessoal de Nível Superior - Brasil (CAPES) - Código de Financiamento 001, que financiou esta pesquisa.

Rachel Matos Rocha: Universidade Federal do Mato Grosso do Sul, Campo Grande, MS, Brasil.

E-mail: rachelrmr@gmail.com

Link para o currículo Lattes: http://lattes.cnpq.br/1236719748827342

Milton Augusto Pasquotto Mariani: Universidade Federal do Mato Grosso do Sul, Campo Grande, MS, Brasil.

E-mail: miltmari@terra.com.br

Link para o currículo Lattes: http://lattes.cnpq.br/0935409945176042

Dyego de Oliveira Arruda: Centro Federal de Educação Tecnológica Celso Suckow da Fonseca, Rio de Janeiro, RJ, Brasil.

E-mail: dyego.arruda@gmail.com

Link para o currículo Lattes: http://lattes.cnpq.br/5222976964204691

Luiz Miguel Renda dos Santos: Universidade Federal do Mato Grosso do Sul, Campo Grande, MS, Brasil.

E-mail: luiz.renda@ufms.br

Link para o currículo Lattes: http://lattes.cnpq.br/4926698868447487

Data de submissão: 31 de janeiro de 2019

Data de recebimento de correções: 28 de fevereiro de 2019

Data do aceite: 28 de fevereiro de 2019

Avaliado anonimamente 